\title{
Molecular survey of pyrethroid resistance mechanisms in Mexican field populations of Rhipicephalus (Boophilus) microplus
}

\author{
Rodrigo Rosario-Cruz • Felix D. Guerrero • Robert J. Miller • \\ Roger Ivan Rodriguez-Vivas • Mary Tijerina • Delia Ines Dominguez-Garcia • \\ Ruben Hernandez-Ortiz • Anthony J. Cornel • Rory D. McAbee • \\ Miguel Angel Alonso-Diaz
}

Received: 24 October 2008 / Accepted: 10 June 2009 / Published online: 30 June 2009

(C) The Author(s) 2009. This article is published with open access at Springerlink.com

\begin{abstract}
Susceptibility to synthetic pyrethroids (SP's) and the role of two major resistance mechanisms were evaluated in Mexican Rhipicephalus microplus tick populations. Larval packet test (LPT), knock-down $(k d r)$ PCR allele-specific assay (PASA) and esterase activity assays were conducted in tick populations for cypermethrin, flumethrin and deltamethrin. Esterase activity did not have a significant correlation with $\mathrm{SP}^{\prime}$ 's resistance. However a significant correlation $(p<0.01)$ was found between the presence of the sodium channel mutation, and resistance to SP's as measured by PASA and LPT respectively. Just over half the populations (16/28) were cross-resistant to flumethrin, deltamethrin and cypermethrine, $21.4 \%$ of the samples $(6 / 28)$ were susceptible to all of the three pyrethroids 10.7 of the samples (3/28) were resistant to
\end{abstract}

R. Rosario-Cruz $\cdot$ R. Hernandez-Ortiz

Centro Nacional de Investigacion Disciplinaria

en Parasitologia Veterinaria,

Carr. Fed. Cuernavaca-Cuautla \# 8534. Col. Progreso,

C.P. 62550. Jiutepec,

Morelos, Mexico

F. D. Guerrero

Knipling-Bushland US Livestock Insect Research Laboratory, USDA-ARS, 2700 Fredericksburg Road,

Kerrville, TX 78028, USA

R. J. Miller $\cdot$ M. Tijerina

Cattle Fever Tick Research Laboratory,

USDA-ARS, 22675 N. Moorefield Road,

Edinburg, TX 78541, USA

R. I. Rodriguez-Vivas

Departamento de Parasitologia,

Facultad de Medicina Veterinaria y Zootecnia,

Universidad Autonoma de Yucatan,

Km. 15.5 carretera Mérida-Xmatkuil. CP. 97100. Merida,

Yucatan, Mexico flumethrin, 3.4 of the samples $(1 / 28)$ were resistant to deltamethrin only and $7.1 \%(2 / 28)$ were resistant to flumethrin and deltamethrin. The presence of the $k d r$ mutation correlates with resistance to the SP's as a class. Target site insensitivity is the major mechanism of resistance to SP's in Mexican $R$. microplus field strains, involving the presence of a sodium channel mutation, however, esterase-based, other mutations or combination of mechanisms can also occur.

\section{Introduction}

The southern cattle tick, Rhipicephalus (Boophilus) microplus (Acari: Ixodidae), is a major cattle disease vector, transmit-

D. I. Dominguez-Garcia

Universidad Autonoma Metropolitana Unidad Xochimilco,

Calzada del Hueso 1100,

Mexico, D.F. C.P. 04960, Mexico

A. J. Cornel • R. D. McAbee

Department of Entomology,

UC Davis, Mosquito Control Research Laboratory,

9240 S Riverbend Avenue,

Parlier, CA 93648, USA

M. A. Alonso-Diaz

Centro de Enseñanza Investigacion y Extension en Ganadería

Tropical. Facultad de Medicina Veterinaria y Zootecnia,

Universidad Nacional Autonoma de Mexico,

Martinez de la Torre,

Veracruz, Mexico

R. Rosario-Cruz $(\bowtie)$

Instituto Nacional de Investigaciones Forestales,

Agricolas y Pecuarias,CENID-PAVET,

Carr. Fed. Cuernavaca-Cuautla \# 8534, Col. Progreso, Jiutepec,

Morelos C.P. 62550, Mexico

e-mail: rockdrig@yahoo.com.mx 
ting the pathogens that cause babesiosis and anaplasmosis. Cattle producers incur high costs of acaricides and drugs to improve the general health of their cattle and to prevent outbreaks of tick-borne cattle diseases. Large populations of $R$. microplus are currently widespread in Mexico and this is negatively affecting the competitiveness of Mexican cattle producers in global markets.

Tick eradication programs have eradicated $R$. microplus from the United States, and a quarantine area is maintained along the US-Mexico border in order to prevent the re-entry and monitor all imported livestock (Graham and Hourrigan 1977). However, in Mexico, the National Campaign against Boophilus spp. failed because of the appearance of resistance to organophosphates. Since then, widespread and increasing resistance to organophosphate and pyrethroid acaricides in Mexico is becoming a major concern to the United States, since organophosphate (Miller et al. 2005) and pyrethroid resistant ticks have been found within the United States (Miller et al. 2007a). In addition, a pyrethroid resistant tick strain has been isolated from the border State of Coahuila, México which possesses 99\% homozygous resistant individuals (Miller et al. 2007b). This finding legitimizes and puts significant pressures on the tick eradication/ quarantine efforts in the USA. In fact, a recent news release from the Texas Animal Health Commission on July 3th 2008, informed that, "Fever ticks, capable of carrying and transmitting deadly 'tick fever' to cattle, have been detected on livestock or wildlife on 139 texas pasture during the past 12 months outside the quarantine areas in Starr and Zapata Counties" (http://www.tahc.state.tx.us).

The intensive use of DDT for more than 20 years likely led to the selection of heritable resistance not only to DDT and its analogs but also to the currently used SP's (Georghiou 1986; Brattsten et al. 1986). Research is still ongoing to understand the mechanisms of resistance to pyrethroids in $R$. microplus but at least two mechanisms have so far been incriminated. The most strongly supported mechanism, also ubiquitous among multiple medically and veterinary important arthropods is known as "Knockdown resistance" or $k d r$ type resistance. $K d r$-type resistance is an insensitive target site form of resistance caused by selection of nucleotide mutations in the para-type sodium channel gene. The protein coded by this gene functions in voltage-sensitive sodium channeling in nerve membranes (Sattelle and Yamamoto 1988, Narahashi 1996). DDT and SP's have lower binding affinities to the $k d r$-type altered forms of this protein (Soderlund 1997, Soderlund and Knipple 1999) which in turn renders the arthropods bearing these forms more resistant to DDT and SP's. A PCR-Allele specific assay (PASA) has been developed (Guerrero, et al. 2001) for detection of a Phe to Ile substitution within the domain III S6 segment from the para-type sodium channel gene; (He et al. 1999). Studies have shown that this mutation correlates with flumethrin, deltamethrin, and cypermethrin resistance in Mexican tick populations (Jamroz et al. 2000; Rosario-Cruz et al. 2005). The second and less understood mechanism involves esterase enzyme-mediated metabolic detoxification. Multiple assays have been developed to detect higher expression of esterases via gene amplification (Mouches et al. 1986; Field et al. 1988) and over-transcription (Fournier et al. 1992) using colorimetric polyacrylamide gel and test tube type assays in ticks (Miller et al. 1999; Rosario-Cruz et al. 1997; Soberanes et al. 2005). Single aminoacid substitution has been implicated in convertion of a carboxylesterase to an organophosphorous hydrolase that confers insecticide resistance on a blow fly (Newcomb et al. 1997). A point mutation of a specific esterase gene supported by bio-assay evidence and increased permethrin hydrolysis of tick homogenates was found to correlate with resistance to $\mathrm{SP}^{\prime} \mathrm{s}$ in a population of ticks from Coatzacoalcos (Hernandez et al. 2000; Jamroz et al. 2000). Interestingly, the $k d r$ mutation was absent in the Coatzacoalcos population suggesting that there are at least two independent pyrethroid resistant mechanisms present in Mexican B. microplus. For surveillance purposes a PCR assay coupled with a EcoR I digestion of the amplified product was designed to identify the presence of an esterase point mutation (Hernandez et al. 2002). Since then this point mutation has been found in numerous Brazilian $R$. microplus populations and resistance to permethrin was moderately high in populations with high numbers of homozygous individuals present in them (Baffi et al. 2007). More recently another mutation in the domain II S4-5 linker of the para-sodium channel that is associated with resistance to SPs in the cattle tick Rhipicephalus (Boophilus) microplus from Australia, has been found. A cytosine to adenine mutation at position 190 within the $R$. microplus sodium channel gene sequence previously reported by $\mathrm{He}$ et al. (1999), results in an amino acid substitution from leucine in the susceptible strain to isoleucine in the resistant strain. A similar mutation has been shown to confer SP resistance in the whitefly, Bemisia tabaci, but has not been described previously in ticks (Morgan et al. 2009). Using a quantitative PCR assay to screen field and laboratory populations of ticks showed that homozygote allelic frequencies correlated highly with the survival percentage at the discriminating concentration of cypermethrin.

As a part of an ongoing survey in Mexico to examine the spread of resistance in $R$. microplus we conducted multiple acaricide susceptibility tests on larvae reared from females collected at multiple locations in the state of Yucatan where SP's are widely used for tick control on cattle ranches. During this survey we also examined association between $\mathrm{SP}^{\prime} \mathrm{s}$ resistance, the presence of the para-type sodium channel mutation and general esterase activity. Knowledge 
of susceptibility status and mechanisms of resistance are invaluable to advise cattle owners of what alternative tick control strategies to use.

\section{Materials and methods}

Tick samples

R. microplus adult females were collected of cattle from twenty eight ranches in the state of Yucatan. The Yucatan State is located in the Southeast area of Mexico between the co-ordinates $19^{\circ} 30^{\prime}$ and $21^{\circ} 35^{\prime}$ North latitude, and $87^{\circ} 30^{\prime}$ and $90^{\circ} 24^{\prime}$ West longitude of the Greenwich meridian. The climate in Yucatan is sub-humid tropical (Awo), with an annual mean temperature of $27^{\circ} \mathrm{C}\left(17-35^{\circ} \mathrm{C}\right)$, annual mean relative humidity of $80 \%$ and annual rainfall of 800 $900 \mathrm{~mm}$ (INEGI 1997) which is optimal for $R$. microplus infestations.

In each farm, 20-30 R. microplus engorged females were collected of at least 10 cattle and transported to the Parasitology Laboratory of the Veterinary Medicine College from the Autonomous University of Yucatan. Upon arrival, engorged females were placed into Petri dishes and incubated in the dark at $27 \pm 1.5^{\circ} \mathrm{C}$ and $85-86 \%$ relative humidity (Cen et al. 1998). The eggs laid from all females from each population were combined and transferred into two $10 \mathrm{ml}$ glass tubes with a cotton cap, to allow larval hatching. Larval packet test (LPT) acaricide susceptibility assays (Kemp et al. 1998) were performed on 7-14 d old larvae from one of the tubes. The larvae in the other tube were frozen at $-70^{\circ} \mathrm{C}$ and used for later esterase activity and $k d r$-diagnostic PCR assays.

\section{Larval packet test}

The modified larval packet test (LPT) (Stone and Haydock 1962) was used to test pyrethroid resistance. Briefly, technical grade acaricide dissolved in a mixture of trichloroethylene and olive oil (2:1 ratio) was used to treat filter papers that were then set for $2 \mathrm{~h}$ in a fume hood to allow trichloroethylene to evaporate before being folded into packets using bulldog clips. Approximately $100 R$. microplus larvae were added into the treated filter papers packets for each acaricide, which was then sealed with additional bulldog clips and placed in an incubator $\left(27^{\circ} \mathrm{C}\right.$ and $85 \%-86 \% \mathrm{RH}$ ). The discriminating concentration (DC) used was: $0.01 \%$ flumethrin, $0.009 \%$ deltamethrin and 0.05\% cypermethrin (Santamaría 1992). The DC used was calculated by doubling the lethal concentration $99.9 \%$ (LC99) derived from a series of tests conducted with a susceptible strain ("Media Joya" reference strain) (Kemp et al. 1998).
The treated larvae were exposed $24 \mathrm{~h}$ to the acaricides and the numbers of live and dead larvae were counted to calculate the percentage of larval survival.

Resistance was classified according to the class of the acaricide (Pyrethroids $=$ Py) and then the specific pyrethroid (flumethrin $=\mathrm{F}$, deltamethrin $=\mathrm{D}$ and cypermethrin $=\mathrm{C}$ ). For instance Py/D referred to ticks resistant to deltamethrin only; $\mathrm{Py} / \mathrm{F}$ resistant to flumethrin only, Py/C resistant to cypermethrin only; and Py/F-D-C referred to ticks resistant to all three pyrethroids.

\section{$K d r$ Allele specific PCR assay conditions}

Larval genomic DNA isolation and genotyping by PASA were performed as described by Guerrero et al. (2001) in thin-walled $0.5 \mathrm{ml}$ micro centrifuge tubes using $20-\mu 1$ reactions optimized for primer annealing temperature and $\mathrm{MgCl}_{2}$ concentration. Final optimized reaction condition consisted of $1 \mu \mathrm{l}$ of genomic DNA homogenate from a single tick larva, 20 pmol of each primer, $10 \mathrm{mM}$ Tris (hydroxymethyl) aminomethane hydrochloride $\mathrm{pH}=8.3$, $50 \mathrm{mM} \mathrm{KCl}, 0.05 \mathrm{mM}$ each dNTP, $1.75 \mathrm{mM} \mathrm{MgCl}_{2}$, and $0.1 \mu \mathrm{l}$ of 1:1 vol:vol mix of AmpliTaq DNA polymerase (5 U/ $\mu$ l stock), and TaqStart antibody (1.1 $\mu \mathrm{g} / \mu \mathrm{l}$ stock). Amplification was carried out using a DNA engine programmed for $96^{\circ} \mathrm{C}$ for 2 min followed by 37 cycles, each consisting of denaturation at $94^{\circ} \mathrm{C}$ for $1 \mathrm{~min}$, annealing at $60^{\circ} \mathrm{C}$ for $1 \mathrm{~min}$, and extension at $72^{\circ} \mathrm{C}$ for $1 \mathrm{~min}$. The program also included a final extension step at $72^{\circ} \mathrm{C}$ for $7 \mathrm{~min}$. Reaction products were fractionated on $2.5 \%$ NuSieve agarose TBE gels and DNA visualized by staining with GelStar DNA staining dye and UV illumination. The following primers were used 5'-TTATCTTCGGCTCCT TCT-3' (wild type-specific sense), 5'-TTATCTTCGGCTC CTTCA-3' (mutant-specific sense), and 5'-TTGTTCATTG AAATTGTCGA-3' (non-specific-antisense).

At least twenty five individual larvae from each tick family were tested to determine $k d r$-genotype frequencies and "RR" was used to designate homozygous resistant, "RS" for heterozygous and "SS" for homozygous susceptible.

\section{Esterase assay}

Larvae (100 mg) were pulverized using a mortar and pestle prechilled to $-70^{\circ} \mathrm{C}$ followed by resuspension in $2 \mathrm{ml}$ of phosphate buffered saline (PBS) $\mathrm{pH}$ 7.2. Total protein content was estimated in each sample after 5 min centrifugation at 10,000 X g, using the Bradford reagent (Bradford 1976). Specific activity of general esterases was determined for each strain using the method reported by Dary et al. (1990), based on hydrolysis of $\alpha$-naphthyl acetate in the presence of Triton X-100, using $50 \mu \mathrm{g}$ of protein for each $1 \mathrm{ml}$ reaction and reading absorbance at $538 \mathrm{~nm}$. 
Data analysis

Correlations between Acaricide susceptibility (\% survival), esterase activity (U/liter) and $k d r$-genotype (RR, RS, and SS) were estimated using Pearson's correlation coefficients.

\section{Results}

\section{Bioassays}

Larval Packet Test toxicological responses at a specific discriminating concentration (DC) for each pyrethroid, esterase activity measurements and $k d r$-genotype for each $R$. microplus population are shown in Table 1. Figure 1 depicts frequencies of populations falling into one or other cross resistant pyrethroid type or category. Twenty one percent $(6 / 28)$ populations examined were susceptible to all three SP's. One population was susceptible to flumethrin and cypermethrin but not entirely to deltamethrin (Py/D type), three populations were susceptible to deltamethrin and cypermethrin but not entirely to flumethrin (Py/F type), one population was susceptible to cypermethrin but not to flumethrin and deltamethrin (Py/F-D). The percent survival of all families resistant to two of the SP's ranged from 89 to 98\% for flumethrin and 91-93 for deltamethrin. All families variably resistant to cypermethrin $(60 \%$ of the families (17/ 28)) were resistant to the other two SP's (Py/F-D-C type). Field samples highly resistant to cypermethrin (0-80 mortality) were also highly resistant to flumethrin (0-54\% mortality) and deltamethrin (0-48.28\% mortality). Families not highly resistant to cypermethrin (81-98.13\% mortality) were also not highly resistant to flumethrin (68.85 to $97.97 \%$ mortality) and deltamethrin (75.35 to $96.32 \%$ mortality).

Esterase activity

Correlation between larval survival and esterase activity, are represented in Fig. 2 (a-c). Correlation coefficients for deltamethrin, flumethrin and cypermethrin were $0.07,0.13$ and 0.1 respectively, $(p>0.05)$ showing no significant association between larval survival and general esterase activity. The two populations with the highest esterase activity (5 or more U/liter, J-004, and AB-063; Table 1), were not highly resistant to any of the pyrethroids. All of the J004 larvae were of the SS $k d r$ genotype and AB-063 larvae had only a low frequency of the resistant $k d r$ allele. There was one resistant to all three SP's strain $(97.87 \%$ overall survival) showing $0.0 \%$ of RR and $92 \%$ of $\mathrm{RS}$ genotype frequency, with $3 \mathrm{U} / \mathrm{L}$ of general esterase activity (Table 1) suggesting the presence of a different point mutation, or an alpha naphtyl acetate non detectable esterase based mechanism.
$K d r$ Allele specific PCR genotyping

A heterogeneous spread of the $k d r$-genotypes was found among the Yucatan tick populations. Correlation between larval survival and $k d r$ genotype are represented in Fig. 3 (a-c). The allele frequency of the Para-type sodium channel mutation, ranged from $4 \%$ to $100 \%$, and the RR + RS genotype was found in $78.6 \%$ of the samples and only $21.4 \%$ of the samples were detected as susceptible to SP's by this mechanism (100\% of SS genotype). Data show that $78.6 \%$ out of the 28 samples collected were resistant at least to one SP and only $60.71 \%$ showed the phenotype Py/F-D$\mathrm{C}$, and $17.89 \%$ was resistant to one or two $\mathrm{SP}^{\prime} \mathrm{s}, 3.5 \%$ was Py/F-D, 10.7 was Py/F and 3.5\% was Py/D. These results show that $60.71 \%$ of the tick populations are resistant to SP's due to the presence of the sodium channel mutation, however, there are $17.89 \%$ of the populations that are resistant to one or two $\mathrm{SP}^{\prime}$ s, whose mechanism of resistance is not clear, but most probably can be due to a different substitution within the sodium channel gene, since no differences were found between esterase activity and the survival rate. There was only one resistant strain ( $97.87 \%$ overall survival) showing $0.0 \%$ of RR and $92 \%$ of RS genotype frequency, theoretically this strain should be phenotypically susceptible; however it was resistant to all kind of SP's.

\section{Discussion and conclusions}

Larvae reared from $R$. microplus female tick populations from 28 cattle ranches in the state of Yucatan (Mexico) were examined for susceptibility to the three commonly used SP's, cypermethrin, deltamethrin and flumethrin. Susceptibility assays were performed using LPT (Stone and Haydock 1962) using filter paper envelopes impregnated with a previously established DC, which was twice the LC99 for the reference susceptible strain (Kemp et al. 1998) for each of the three SP's. In addition, to give insights into possible modes of resistance, frequencies of the $k d r$-type mutant alleles measured by the PASA system and esterase activities using a general esterase substrate were determined within these tick populations. Cattle owners have preferred to use various SP's formulations in México for several years since widespread resistance to organophosphates was recorded in the early 1980's (Ortiz, et al. 1995).

Populations of ticks most resistant to cypermethrin and other SP's were found on multiple cattle ranches but were to some extent concentrated in central and southern Yucatan. Of particular concern was that over half the populations sampled displayed resistance to all three pyrethroids and only 4 out of 28 populations were still fully susceptible to these compounds. Resistance to pyrethroids in $R$. microplus was already recorded in Mexico over ten years ago such in the "Mora" strain (Ortiz et al. 


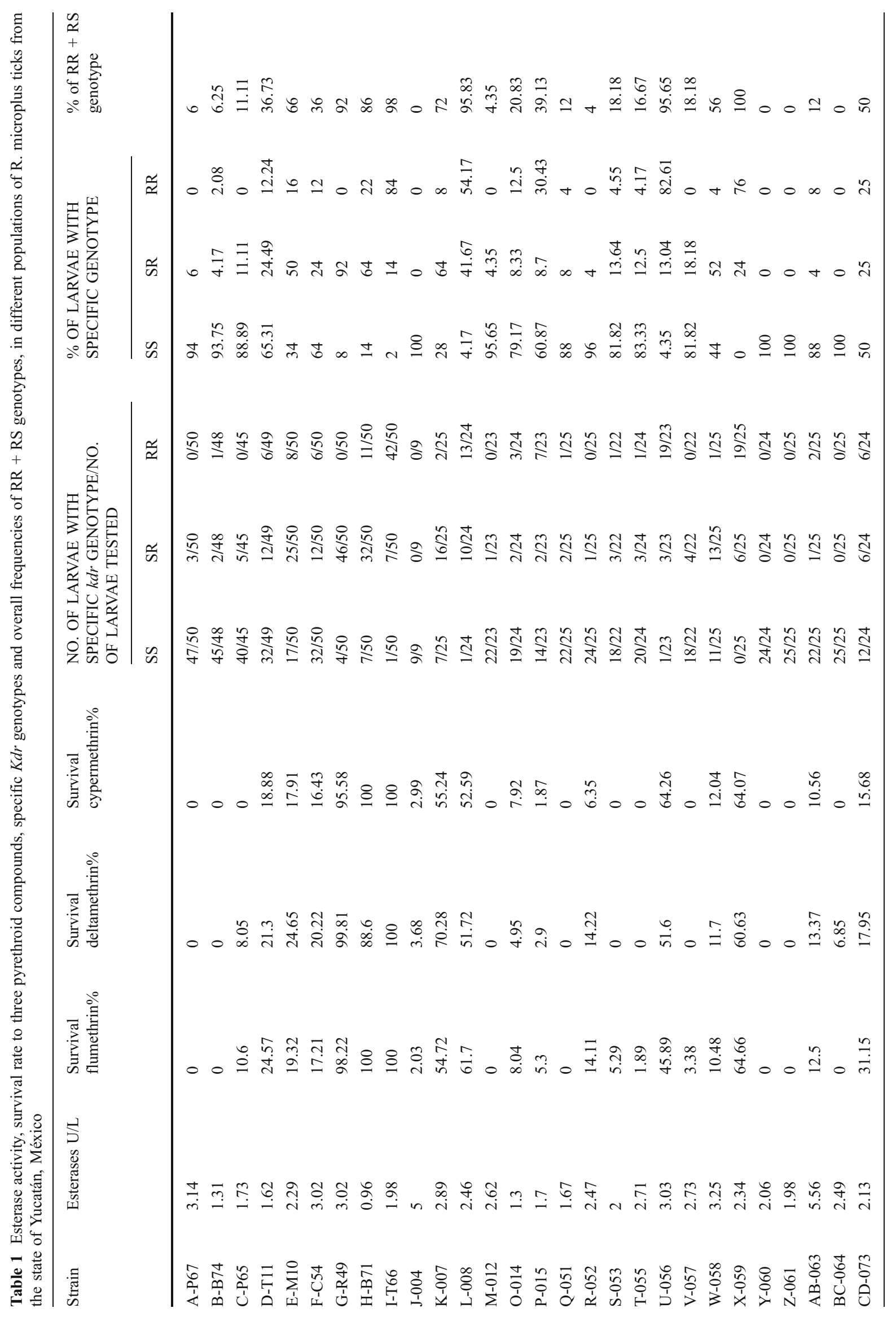




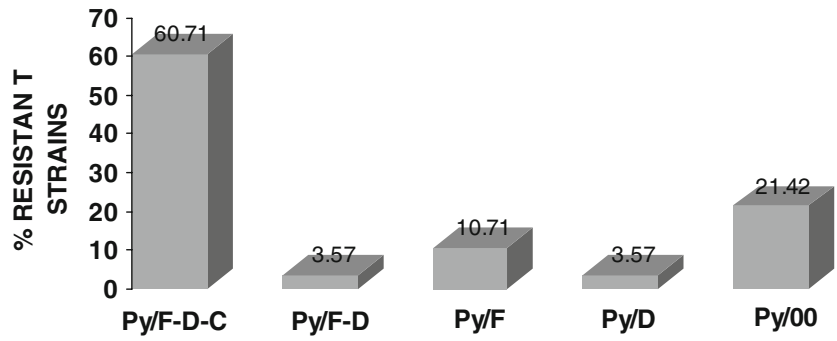

Fig. 1 Graph bar showing frequency distribution of different types of susceptibility to pyrethroids as measured by LPT using a discriminant dose for each pyrethroid. Data show percentage obtained from 28 samples collected in Yucatán, Mexico. Py $=$ Pyrethroid resistance, $\mathrm{F}=$ flumethrin, $\mathrm{D}=$ Deltamethrin, $\mathrm{C}=$ cypermethrin, $\mathrm{F}-\mathrm{D}-\mathrm{C}=$ resistance to flumethrin, deltamethrin and cypermethrin, $00=$ susceptibility to pyrethroids as a class

a

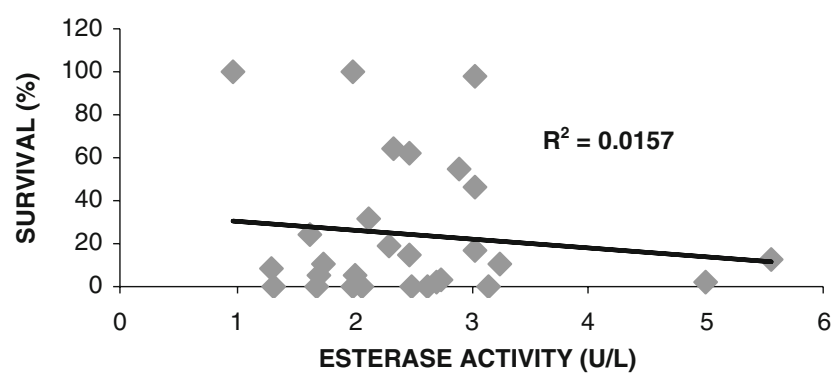

b
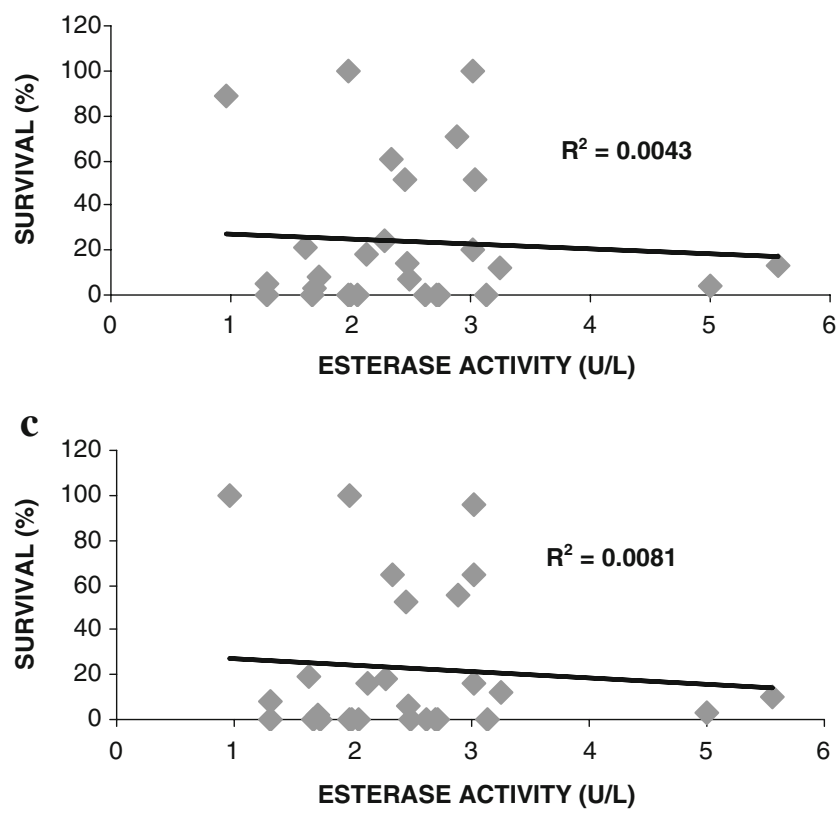

Fig. 2 Correlation $(p>0.05)$ between the survival rate as measured by LPT and general esterase activity measured by photocolorimetric assay in international units/liter $(\mathrm{U} / \mathrm{L})$ for flumethrin $\left(\mathrm{r}^{2}=0.0157\right)$ (a), deltamethrin $\left(\mathrm{r}^{2}=0.0043\right)$ (b) and cypermethrin $\left(\mathrm{r}^{2}=0.0081\right)(\mathrm{c})$ $(P>0,05)$
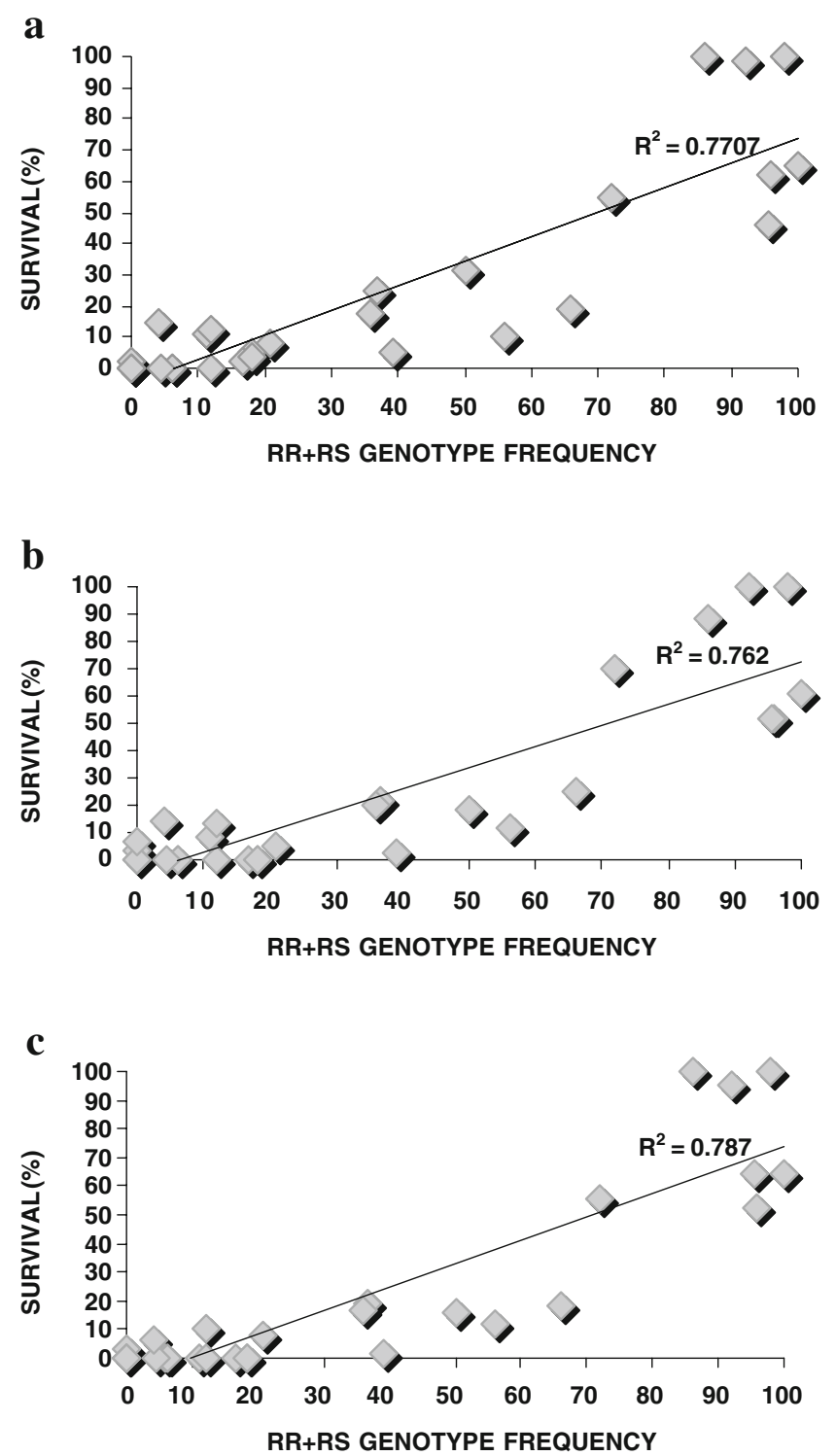

Fig. 3 Correlation $(p<0.01)$ between the survival rate $(\%)$ as measured by the LPT and the (RR + RS) genotype frequency (\%) for flumethrin $\left(\mathrm{r}^{2}=0.77\right)(\mathrm{a})$, deltamethrin $\left(\mathrm{r}^{2}=0.76\right)(\mathrm{b})$ and cypermethrin $\left(r^{2}=0.78\right)(c)$, as measured by the PASA

1995). It is now clear that resistance has spread and could become quite disastrous given the high costs of treating tick infestations with more expensive acaricides such as amitraz and fipronil. Heterogeneity of susceptibility to three compounds was found as multiple populations were not resistant to all three but to one or two of the SP'S compounds as has been found in other parts of Mexico such as in the "Aldama" strain (Ortiz et al. 1995). This heterogeneity of toxic response phenotypes to different SP's suggest that there are likely multiple mechanisms of resistance present in R. microplus that each have their own SP selective metabolizing enzymes or different types of target site insensitivity properties. 
Insensitive target site ( $k d r$ type) resistance, which is now quite ubiquitous among disease vector and other arthropod species, is present in R. microplus. Past (Rosario-Cruz et al. 2005) and this study confirms its presence in multiple field populations of $R$. microplus. These findings were also confirmed by Methods based on the melting temperature difference of amplified allele-specific DNA fragments in individual larvae from México but not from the Australian strains. Different resistance mechanisms have apparently developed independently between Australian and Mexican strains of R. microplus (Chen et al. 2009). On the other hand.a different mutation similar to that found in Bemicia tabaci within the same B. microplus sodium channel gene was found in the Australian ticks but not present in Mexican strains (Morgan et al. 2009). In Yucatan high frequencies of RR and RS $k d r$ genotypes were recorded and showed a statistically significant correlation between its presence and low susceptibility to pyrethroids $(P<0.01)$. Multiple different nucleotide substitutions within the voltage gated sodium channel gene can confer resistance to SP's as has been found in malaria vector mosquitoes (Reimer et al. 2008) and other arthropods (Soderlund and Knipple 2003). So far only the Phe to Ile substitution within the domain II S6 segment has been found in Mexican populations of R. microplus (He et al. 1999, Guerrero et al. 2001). Despite the significant correlation between frequency of RR and RS and pyrethroid resistance (Fig. 3), there was one resistant strain $(97.87 \%$ overall survival) showing $0.0 \%$ of RR and $92 \%$ of RS genotype frequency, recent studies have shown that the heterozygous condition show a susceptible genotype (Aguilar-Tipacamú et al. 2008), therefore a heterozygous population must be susceptible. This may indicate that there is another esterase based resistance mechanisms non-detectable by the surrogate substrate alpha-Naphtyl acetate, that can act in unison with or independently of the $k d r$ genotype to confer resistance since this strain (G-R49) showed only a medium level ( $3 \mathrm{U} / \mathrm{L}$ ) of esterase activity. It is also probably that there is a different mutation emerging in tick populations, such as the recent mutation found in Australia (Morgan et al. 2009) in the domain II S4-5 linker of the para-sodium channel that is associated with resistance to SPs in the cattle tick Rhipicephalus (Boophilus) microplus from Australia but not for Mexican strains. The cytosine to adenine mutation at position 190 in the R. microplus sequence AF134216, results in an amino acid substitution from leucine in the susceptible strain to isoleucine in the resistant strain. A similar mutation has been shown to confer SP resistance in the whitefly, Bemisia tabaci, but has not been described previously in ticks. These results show that Mexican and Australian tick strains have selected two different and independent substitutions within the sodium channel gene as mechanisms of resistance to SP's, leading to a similar toxicological phenotype.

Detoxification mediated by carboxylesterases represents one such mechanism for which there is some evidence of it occurring in $R$. microplus. The Coatzacoalcos strain possesses significant enhancement of general and cypermethrin esterase activity. This strain has both duplication of a $62.28 \mathrm{Kd} \mathrm{CzEST9}$ esterase enzyme leading to elevated expression of this gene (Miller et al. 1999, Jamroz et al. 2000, Pruett et al. 2002) and a point mutation of another esterase that together confers quite high resistance to cypermethrin (Hernandez et al. 2002). The $k d r$ mutant allele is absent in the Coatzacoalcos strain so in this case esterase mediated SP mechanism of resistance is not acting in unison but independently of insensitive target site resistance.

In tick samples thus far investigated from Yucatan, pyrethroid resistance conferred by elevated esterases does not appear to be present (Fig. 2). This does not rule out the possibility that a unique esterase that has high $\mathrm{SP}^{\prime} \mathrm{s}$ hydrolysis properties such as the mutant esterase allele found in the Coazacoalcos strain which is not elevated, does not exist in Yucatan and elsewhere in Mexico. The esterase activity assay based on the general alpha naphthyl acetate substrate used in this study might not have picked up the presence of an esterase that is highly selective for hydrolysis of SP's and is not elevated. For instance, Californian populations of the mosquito Culex tarsalis that are very resistant to malathion do not have elevated esterases and a high alpha naphthyl acetate activity. Instead the $C x$ tarsalis have an unamplified esterase B3 gene mutant that rapidly hydrolyzes malathion (Tittiger and Walker 1997). It might thus be more useful to use new generation $\alpha$ - fluorescent cyanoesters as substrates for detection of pyrethroid-selective esterases (Wheelock et al. 2003, Waite et al. 2005).

We also cannot rule out the existence of other resistance mechanisms in $R$. microplus such as detoxification by cytochrome P450 and Glutathion-S Transferase (GST) enzyme systems and possibly even reduced penetration. It is expected that the entire genome of $R$. microplus will be sequenced in the near future and this will likely help immensely in studies to investigate role of gene families such as esterases, P450s and GSTs in detoxifying SP's.

In conclusion, the presence of the $k d r$ mutation correlates with resistance to the $\mathrm{SP}^{\prime} \mathrm{s}$ as a class. Target site insensitivity is the major mechanism of resistance in Mexican $R$. microplus field strains, however, esterasebased, other mutations or combination of mechanisms can also occur. Therefore, surveillance to determine its frequency is recommended. However, whenever large enough tick samples are available, susceptibility bio-assays should be continued to ensure that resistant populations not conferred by $k d r$ type resistance are not missed. SP resistant $R$. microplus are quite widespread in Mexico and serious attempts 
to implement and recommend a resistance management program should be made using alternative "acaricides" and rotations of chemicals with different modes of action, before the use of SP's select the mutation in all those ranches still showing a homozygous SS genotype.

Acknowledgments This project was funded by CONACYTSAGARPA, Mexico. Projects No. 2002-C01-1447 and 2002-C011754. We also want to acknowledge to the CONACyT for the financial support of the student Delia Inés Dominguez García, currently registered in the doctoral graduate program of the UAMXochimilco, México. Special acknowledgements to Kylie Bendele for his critical review and Edgar Castro Saines and Gabriela Aguilar Tipacamú for their technical assistance. All experiments comply with the current laws of Mexico and USA.

Open Access This article is distributed under the terms of the Creative Commons Attribution Noncommercial License which permits any noncommercial use, distribution, and reproduction in any medium, provided the original author(s) and source are credited.

\section{References}

Aguilar-Tipacamú G, Miller RJ, Hernández-Ortiz R, Rodriguez-Vivas RI, Vásquez-Peláez C, García-Vázquez Z, Olvera-Valencia FA, Rosario-Cruz R (2008) Inheritance of pyrethroid resistance and a sodium channel gene mutation in the cattle tick Boophilus microplus. Parasitol Res 103:633-639

Baffi MA, de Souza GR, Vieira CU, de Sousa CS, Gourlart LR, Bonetti AM (2007) Identification of point mutations in a putative carboxylesterase and their association with acaricide resistance in Rhipicephalus (Boophilus) microplus (Acari: Ixodidae). Vet Parasitol 148:301-309

Bradford MM (1976) A rapid and sensitive method for the quantitation of microgram quantities of protein utilizing the principle of protein dye binding. Analyt Biochem 72:248-254

Brattsten LB, Holyoke CW Jr, Leeper JR, Raffa KF (1986) Insecticide Resistance: Challenge to Pest Management and Basic Research. Science 231:1255-1260

Cen AJ, Rodríguez-Vivas RI, Domínguez AJL, Wagner G (1998) Studies on the effect of infection by Babesia $s p$ on oviposition of Boophilus microplus engorged females naturally infected in the Mexican tropics. Vet Parasitol 78:253-257

Chen AC, He H, Temeyer KB, Jones S, Green P, Barker SC (2009) A survey of Rhipicephalus microplus populations for mutations associated with pyrethroid resistance. J Econ Entomol 102:373380

Dary O, Georghiou GP, Parsons E, Pasteur N (1990) Microplate adaptation of Gomori's assay for quantitative determination of general esterase activity in single insects. J Econ Entomol 83:2187-2192

Field LM, Devonshire AL, Forde BG (1988) Molecular evidence that insecticide resistance in peach-potato aphid (Myzus persicae Sulz.) results from amplification of an esterase gene. Biochem J 251:309-312

Fournier D, Bride JM, Poirie M, Bergé JB, Plapp FW (1992) Insect glutathione transferase: Biochemical characteristics of the major forms from houseflies susceptible and resistant to insecticides. $\mathrm{J}$ Biol Chem 267:1840-1845

Georghiou GP (1986) Pesticide resistance: Strategies and tactics for managements. Natl Acad Press, Washington DC, pp 14-43
Graham OH, Hourrigan JL (1977) Erradication programs for the arthropod parasites of livestock. J Med Entomol 13:629-658

Guerrero FD, Davey RB, Miller RJ (2001) Use of an allele-specific polymerase chain reaction assay to genotype pyrethroid resistant strains of Boophilus microplus (Acari: Ixodidae). J Med Entomol 38:44-50

He H, Chen AC, Davey RB, Ivie GW, George JE (1999) Identification of a point mutation in the para-type sodium channel gene from a pyrethroid-resistant cattle tick. Biochem Biophys Res Com 261:558-561

Hernandez R, He H, Chen AC, Waghela SD, Wayne Ivie G, George JE, Wagner GG (2000) Identification of a point mutation in an esterase gene in different populations of the southern cattle tick, Boophilus microplus. Insect Biochem Mol Biol 30:969-977

Hernandez R, Guerrero FD, George JE, Wagner G (2002) Allele frequency and gene expression of a putative carboxylesteraseencoding gene in a pyrethroid resistant strain of the tick Boophilus microplus. Insect Biochem Mol Biol 32:1009-1016

Instituto Nacional de Estadística, Geografía e Informática. INEGI. (1997). Anuario estadístico del estado de Yucatán. Instituto Nacional de Estadística, Geografía e Informática. México.

Jamroz RC, Guerrero FD, Pruett JH, Oehler DD, Miller RJ (2000) Molecular and biochemical survey of acaricide resistance mechanisms in larvae from Mexican strains of the southern cattle tick, Boophilus microplus. J Insect Physiol 46:685-695

Kemp DH, Thulner F, Gale KR, Nari A, Sabatini GA (1998) Acaricide resistance in the cattle ticks Boophilus microplus and Boophilus decoloratus. Report to the Animal Health Services FAO. pp. 1-32

Miller RJ, Davey RB, George JE (1999) Characterization of pyrethroid resistance and susceptibility to coumaphos in Mexican Boophilus microplus (Acari: Ixodidae). J Med Entomol 36:533-538

Miller RJ, Davey RB, George JE (2005) First report of organophosphateresistant Boophilus microplus (Acari: Ixodidae) within the United States. J Med Entomol 42:912-917

Miller RJ, Davey RB, George JE (2007a) First report of permethrinresistant Boophilus microplus (Acari: Ixodidae) collected within the United States. Med Entomol 44:308-315

Miller RJ, Rentaría JA, Martinez HQ, George JE (2007b) Characterization of permethrin-resistant Boophilus microplus (Acari: Ixodidae) collected from the state of Coahuila, Mexico. J Med Entomol 44:895-897

Morgan JA, Corley SW, Jackson LA, Lew-Tabor AE, Moolhuijzen PM, Jonsson NN (2009) Identification of a mutation in the parasodium channel gene of the cattle tick Rhipicephalus (Boophilus) microplus associated with resistance to synthetic pyrethroid acaricides. Int J Parasitol 39:775-779

Mouches C, Pasteur N, Bergé JB, Hyrien O, Raymond M, de Saint Vincent BR, de Silvestri M, Georghiuou JP (1986) Amplification of an esterase gene is responsible for insecticide resistance in a California Culex mosquito. Science 233:778

Narahashi T (1996) Neuronal ion channels as the target sites of insecticides. Pharmacol Toxicol 79:1-14

Newcomb RD, Campbell PM, Ollis DL, Cheah E, Russell RJ, Oakeshott JG (1997) A single aminoacid substitution converts a carboxylesterase to an organophosphorous hydrolase and confers insecticide resistance on a blow fly. Proc Natl Acad Sci 94:7464-7468

Ortiz EM, Santamaría VM, Ortiz NA, Soberanes CN, Osorio MJ, Franco BR, Martinez IF, Quezada DR, Fragoso SH (1995) Characterization of Boophilus microplus resistance to ixodicides in México. In: Seminario internacional de Parasitología Animal Pp 58-66. Acapulco, México

Pruett JH, Guerrero FD, Hernandez R (2002) Isolation and identification of an esterase from a Mexican strain of Boophilus microplus (Acari: Ixodidae). J Econ Entomol 95:1001-1007

Reimer LJ, Fondjo E, Patchaoke S, Diallo B, Lee Y, Traore C, Lanzaro GC, Cornel AJ (2008) Relationship between $k d r$ mutation and 
resistance to pyrethroids and DDT insecticides in natural populations of Anopheles gambiae. J Med Entomol 45:260-266

Rosario-Cruz R, Miranda ME, Garcia VZ, Ortiz EM (1997) Detection of esterase activity in susceptible and resistant Boophilus microplus tick strains. Bull Entomol Res 87:197-202

Rosario-Cruz R, Guerrero FD, Miller RJ, Rodriguez-Vivas RI, Domínguez-García DI, Cornel AJ, Hernandez-Ortiz R, George JE (2005) Roles played by esterase activity and by a sodium channel mutation involved in pyrethroid resistance in populations of Boophilus microplus (Acari: Ixodidae) collected from Yucatán, Mexico. J Med Entomol 42:1020-1102

Santamaría VM (1992) Determinación de la dosis discriminantes a tres piretroides sintéticos en la cepa Boophilus microplus susceptible CENAPA. II Congreso Nacional de Parasitología. Veracruz, México, pp 2-4

Sattelle DB, Yamamoto D (1988) Molecular targets of pyrethroid insecticides. Adv Insect Physiol 20:147-213

Soberanes-Céspedes N, Rosario-Cruz R, Santamaría VM, GarcíaVazquez Z (2005) General esterase activity variation in the cattle tick Boophilus microplus and its relationship with organophosphate resistance. Tec Pecu Mex 43:239-246

Soderlund DM (1997) Molecular mechanisms of insecticide resistance. In: Sjut V (ed) Molecular Mechanisms of Resistance to Agrochemicals. Springer, Berlin, pp 21-56
Soderlund DM, Knipple DC (1999) Knockdown resistance to DDT and pyrethroids in the house fly (Diptera: Muscidae): from genetic trait to molecular mechanism. Ann Entomol Soc Amer 92:909-915

Soderlund DM, Knipple DC (2003) The molecular biology of knockdown resistance to pyrethroids insecticides. Insect Biochem Mol Biol 33:563-577

Stone BF, Haydock KP (1962) A method for measuring the acaricide susceptibility of the cattle Boophilus microplus (Can). Bull Entomol Res 53:563

Tittiger C, Walker VK (1997) Isolation and characterization of an unamplified esterase B3 gene from malathion-resistant Culex tarsalis. Biochem Genet 35:119-138

Waite TD, Huang H, Inceoglu B, Christiansen JS, McAbee RD, Hammock BD, Cornel AJ (2005) Improved methods for identifying elevated enzyme activities in pyrethroid-resistant mosquitoes. Proceedings of the 2005 Annual Mosquito and Vector Control Association of California Conference 73:131136

Wheelock CE, Wheelock AM, Zhang R, Stok JE, Morisseau C, Le Valley SE, Green CE, Hammock BD (2003) Evaluation of $\alpha$ cyanoesters as fluorescent substrates for examining interindividual variation in general and pyrethroid-selective esterases in human liver microsomes. Anal Biochem 315:208-222 